\title{
Opening the Psychiatric Hospital and Bringing the City Inside. Contradiction and Reflexivity in a Case of Urban Innovation by Tommaso Vitale, Sciences Po (CEE)
}

\begin{abstract}
The objective of the paper is to explain a case of social innovation in mental health services, moving from a psychiatric hospital, classically a total institution, to a healthier, diversified, and personalized care service. The research was conducted by a participant observation method, on the long run, from 1996 to 2006 in Milan (Italy): more than 25 meeting and 40 semi structured interviews were conducted. It looks at a case of 'social entrepreneurship' in Milan which contributes to the transformation of a large, closed psychiatric hospital into a more open and therapeutic environment for mental health services users, as well as for ordinary citizens of the whole metropolitan area. Most of the literature correctly emphasize governance and administrative capability as crucial variable for satisfaction of needs, recognition of capability and sustainability of projects. The paper shows the relevance of exogenous resources, nonlocal mobilisations, and loosely connected social movement networks to enact communicative spaces and challenge closed and inertial policy communities.
\end{abstract}

Keywords: Total Institution; Psychiatric Hospital; Social Enterprise; Urban Regeneration; Urban Festival; Policy Community; Institutional Inertia; Implementation; Local Welfare; Exogenous Change.

Italy has a strong tradition of participatory planning for social policies at the local level. In the mental health sector, a reform has been introduced in 1978 to close psychiatric hospitals (henceforth "PH") and empower the decentralization of community care centers. Looking at the spatial distribution of social care agencies and services, many scholars have recognized that the reform has been effective involving community-based organizations and social enterprises (de Leonardis, et al, 1996). However, in 1996 the PH of Milan was still working. Without connections and ties in the local neighborhood, it was completely disembedded from the local community. Otherwise, in Milan community-based actors and urban movements were more and more involved in social policies and services; but only professionals of the mental health community were looking at the psychiatric hospital. The $\mathrm{PH}$ was closed space, not interesting for social actors investing in innovating community care and housing inclusion in the mental health sector. The inertia of the PH was related to the closeness of the place, and to the closeness of the policy community. In this article I stress the organisational processes which are capable of increasing reflexivity in social innovation dynamics. I will be concentrating above all on cultural practices and group styles (Eliasoph, Lichterman, 
2003) which structure organising processes. The paper intends to show a case where people involved in social innovation activities make reference to strategies and political cultures elaborated in a social movement. I maintain that in this case it is very important for social innovators to be supported by the past, by previous experiences. In this sense, I stress the power of networks as a vector of the circulation of ideas and strategies, and the dialectics between history and radical change.

More precisely, I will be looking at Olinda, a social cooperative created with the aim of transforming a large, closed psychiatric hospital in the northern suburbs of Milan ${ }^{1}$ into a more open and therapeutic environment for mental health services users, as well as for ordinary citizens of the entire metropolitan area. ${ }^{2}$ Olinda used conflicts with health institutions, local authorities and the closest neighbourhoods as a means to advance public discourse, to give legitimacy and dignity to those who had previously been outcasts, and to create innovative institutional arrangements. In this way it has created unprecedented links between care and support for the weaker sectors of the population and cultural opportunities open to the whole population of the Milan metropolitan area. In short, Olinda social innovation is linked to the ability to combine social and economic objectives, working simultaneously on the empowering of disadvantaged people and on the social enjoyment of the city. This case study provides an example of the relationships between radical social innovation and path dependency, paying close attention to the importance of the activities and strategies of past social movements and to how they circulate in network relationships over the years.

To enable a better understanding of the case study, I put it in context.. I present the innovation approach of the Italian sociologist Ota de Leonardis that complements the literature on social innovation by focusing on those organisational processes which allow an increase in the degree of reflexivity of innovative action/interaction. I go on to outline the main features of the De-Institutionalisation movement, the Italian social movement which promotes policy change in the treatment of mental illness (de Leonardis et al., 1996). In this context, I present the Olinda cooperative which,

\footnotetext{
${ }^{1}$ For a detailed GIS description of the Milan metropolitan area, with figures on the social composition of neighbourhoods, please see Pratschke et al. (2021).

${ }^{2}$ The name Olinda was inspired by the story written by Italo Calvino (1978) that tells of the town of Olinda, which develops without generating outer cities.
} 
motivated by an unbearable situation in psychiatric care, broke away from previous paths of coping with the inertia of local institutions. I discuss how Olinda is rooted and supported by cognitive resources (ideas and strategies) emanating from the DeInstitutionalisation network. In the last section, the discussion is focused on a particular feature of the Olinda organizing processes and then, more generally on all the experiences of Social Entrepreneurship promoted by the De-Institutionalisation Movement. This feature is the contradiction between care and work, which multiplies resources for reflexivity on social innovation.

\section{Organising, Reflexivity and Innovation}

Following Moulaert et al. (2005), we may underline at least three meanings of the concept of social innovation: (1) the satisfaction of human needs (the content/product dimension); (2) changes in social relations, especially with regard to governance (the process dimension); and (3) increasing the socio-political capability and access to resources needed to enhance rights to the satisfaction of human needs and participation (the empowerment dimension). In other words, social innovation rests on two pillars: institutional innovation (innovation in social relations, innovations in governance) and innovation in the sense of the social economy, i.e. satisfaction of various needs in local communities (Moulaert, Nussbaumer, 2005). In their survey of the literature, Moulaert et al. (2005) find that different disciplines and approaches tend to stress very different sources, from the dynamic interrelationship between organisation restructuring on the one hand and creative learning on the other, to environmental improvements; from initiative and individual leadership to the importance of social structure as a catalyst, but also as an ensemble of constraints for social innovation in a territorial context at the regional, local, or neighbourhood level. Besides, literature about territorial innovation models tends to emphasise the importance of politics-guided processes of coordination, rather than selection processes promoted by the market; or hybrid forms based also on reciprocity (Moulaert, Sekia, 2003). Empirical findings, starting from case studies of neighbourhood development strategies, show that specific importance is also acquired by multi-scalar alliances and networks through which link exogenous forces with nontraditional local initiatives (Gonzalez, Healey, 2005; Hillier et al., 2004; Moulaert et al., 2010).

In order to gain a profound insight into these dynamic and relational configurations, it is necessary to pay close attention to the importance of the organisational dimension, or more precisely, the processes of organising rather than the 
organisation per se (that is, as something taken for granted). Observing processes of organisation is crucial in order to understand how reflective actors come to the fore. In other words, if sense-making processes enabling reflexivity occur during the organising itself (Weick, 1995), it then becomes necessary to comprehend which kind of organisational process is successful in increasing reflexivity in innovations (Membretti, 2007). Innovation processes are generally contradictory because they de-stabilise existing relations and "open up the 'cracks' and contradictions" (Gonzalez, Healey, 2005). Secondly, innovation processes emerging from interaction between collective actors, are "heterogeneous, kaleidoscopic, often fragmented, internally contradictory" (Swyngedouw, 2005).

Following on from this, in the next paragraph I describe the main characteristics of the 'De-Institutionalization Movement' and spend some time emphasising some of its less well-known features. It is a network that continues to offer room to interesting social innovation. So, it is interesting to explore within this movement the kind of social processes that enable reflexivity in social innovation.

\section{The De-institutionalization Movement}

The 'De-Institutionalization Movement' advocates an alternative approach to the treatment of psychiatric in-patients, promoting institutional arrangements for the reintroduction of in-patients into ordinary life. The main goal of this movement was the closure of the PHs in order to set up territorial networks of mental health services and to create opportunities for professional work. The movement first began in Gorizia in the early 1960s, around the seminal work of the psychiatrist Franco Basaglia (1987). The movement thus started before the Italian protest cycle between 1965 and 1975 (Tarrow, 1990). In 1978, Basaglia was able to bring Parliament to pass a law on the reform of Italy's national psychiatric services (Law 180/78). He was successful in avoiding the ideas of the Radical Party (left-oriented yet with a strong neoliberal ideology), against having such a law and at the same time, he was able to oppose moderate ideas aimed at maintaining and 'humanising' the PH. Unlike other social movements, which fall after the institutionalisation of their claimed reform, this movement continues to maintain networks of informal interactions among a plurality of individuals, groups and associations. It has mobilised different types of individuals, both technicians and nontechnicians. Initially it involved technicians hailing from the psychiatric policy sector, nurses, physicians and social workers. After a while, it also began to mobilise 
politicians, students and left-wing militants. In the years 1968 and 1977 in particular, this movement was regarded with great interest by students, youths and feminist groups (de Leonardis, 1986: 198). The groups involved are also quite varied, covering public agencies, cooperatives, family associations, and so on. Following Mario Diani (2000: 399), I can say that this may be considered a 'new' social movement, for it generates new solidarities and group memberships "which cut across the boundaries of any specific traditional political cleavage, and thus undermine current forms of encapsulation". I may add that this movement has a hybrid character, in the sense that it involves different kinds of actors engaged in a political or cultural conflict, on the basis of certain shared collective strategies.

Before elaborating on these strategies, it is important to analyse the forms of action of this movement and the aims of its mobilisations. Both of these are rather peculiar.

\section{The forms of action}

The movement's forms of action are closely linked to a practical everyday dimension of the transformation of psychiatry. These actions are "highly individualised, based on practice and restricted to the local political sphere" (de Leonardis, 1986: 199).

Over the years at the local level, the movement has changed the practical ways in which a therapy relation takes place, opened the doors to PHs, and has worked towards progressively closing them down. This they have not done drastically (which would risk leaving people on the streets, as has occurred in other countries, above all in the USA), but in an incremental fashion, seeking an individualised path for each person, opening the territorial mental health centres twenty-four hours a day, promoting protected flats whilst maintaining the presence of the workers, and forming work cooperatives. Rooting the various nodes of the network locally has allowed local practices to be closely associated with general causes, in which the acknowledgement of the subjective rights of individuals suffering from health problems was and still is at stake.

Throughout the years, this network has not only been active at the local level, but has also encountered moments of collective vision and mobilisation on a national scale. On this national scale, the movement has structured itself around forms of exchange within local experiences, whether via conventions and workshops, via the movement of workers, or more recently, via the construction of large European projects 
(as the EQUALs) or projects of the World Health Organisation which have engaged with the various local nodes. In this sense, mobilisation at the national level has never been autonomous from the local contexts, but has helped to strengthen them and to spread ideas and cognitive resources. Consequently, at the national level, over the years the movement has neither become institutionalised nor has it taken on a bureaucratic structure, despite being structured as an association (Psichiatria Democratica). With Basaglia's early death in 1980, the leadership of the movement remained fluid and showed "various overlapping forms (charismatic, ringleading, bureaucratic)" (ibid.). The specific characteristics of this movement's forms of action have fostered the establishment of local roots and ensured independence from the left-wing parties (Vitale, 2015).

\section{The objectives of the action}

The specific objective of the movement has always been the transformation of psychiatric institutions. Firstly, the movement seeks the closure and abandoning of the $\mathrm{PH}$ as a place which renders its inmates powerless and increases their chronic dependence upon the institution (Goffman, 1961). The PH is also a place which gathers together those refused or deserted by other institutions of social assistance: people who are impossible to deal with, chronic patients, or people with accumulated problems (Mauri, 1983). The PH is also an institutional device that tends to provide selfjustification and to make itself indispensable. However, beyond the closure of the $\mathrm{PH}$, the movement has always criticised and attempted to overcome the idea of the $\mathrm{PH}$ as a metaphor, as a 'logic of action' as it is understood outside the borders of large PHs, including in small foster centres or territorial services linked to practices of containment, de-personalisation and segregation. According to the movement, the $\mathrm{PH}$ is synonymous with the very idea of 'internship', that is to say, of detention in the name of protection, of the restriction of freedom in the name of freedom from the illness.

In this sense, the Italian movement has acquired a very strong character with respect to the anti-psychiatric movements of other countries, often linked to charismatic figures, such as Ronald Laing in London or Felix Guattari in France. In Italy, the movement has always kept its distance from other countries' attempts to build a 'responsible' territorial structure for psychiatry, that is, individual innovative services which continued nevertheless to rely on the $\mathrm{PH}$ for difficult cases, or which in any case did not make overcoming the $\mathrm{PH}$ a priority target. The temptation to 'take refuge in 
experimentation' has always been criticised, for it develops non-oppressive forms of treatment whilst taking shelter from the obligation to accept any kind of patient (Giannichedda, 2005). In Europe and the USA, these experiments were unable to touch upon either the structure of PHs, or even on the common feeling of danger, shame and consequently of exclusion in the face of mental disease.

On the contrary, the Italian De-Institutionalisation movement, faced with resistance to change (by the institutions, local inhabitants and organised crime), practised something a kin to "passive negation" (Jon Elster, 1979), thus attempting to go beyond the situation of the $\mathrm{PH}$ without reaffirming the need for it. Deinstitutionalisation succeeded in negating the $\mathrm{PH}$ by constructing something different, a situation of exchange and of social, institutional and commercial co-operation in which both the negation and the object of it (the PH) were no longer necessary (de Leonardis, 1990).

\section{The strategies}

From this perspective, we may understand the main strategies implemented by the movement towards de-institutionalisation: the positioning within institutional spaces and the impulse to make the contradictions visible.

The first strategic decision was for the movement to position itself within a specific institutional space, so as to be able to transform this space and at the same time transform the relationship between individuals and the urban context. In this sense, the adopted strategy is one of social innovation, for it seeks to work not only on the mental illness of the individuals, but also on the places and the relations of governance which their transformation may produce. The positioning of the movement within a plurality of institutional spaces at the local level has enabled these to persist over time, even after the approval of a reform. In actual fact, in contrast with other movements which mobilise on campaigns for the promotion of reform, this movement has not ceded the control of the implementation of the reform, 'taking care' of it. Having previously taken steps through other specific innovations, the movement has been able to oversee the implementation of the reform and continues to keep watch on it, without abandoning the political work of contracting and compromise-building with local political parties (de Leonardis, 1986: 204; about the concept of compromise, see Boltanski and Thévenot, 2006). The movement has thus found itself having to persevere (and to adapt itself) over a period of several decades, deciding at all times upon a 'politics of institutions' (de 
Leonardis, 1990), that is, a contentious politics of innovation via the construction of what Basaglia called "infinite institutional machiavellis". In this sense, this movement is not 'anti-institutional': within this movement, criticism of the 'institutionalised' has led to the path of practice, and has become an 'institutionalising' process. At the same time, it maintains a a reflective capacity for reaction and criticism with respect to each of the solutions it has institutionalised (de Leonardis, 1990). In this way, the movement has positioned itself by bringing together a reformist thrust (which I may describe as giving attention to institutions, regulations and consequential logic) on the one hand, and a revolutionary thrust (which I may describe as looking not to standardise, but seeking to subvert order by discussing it, and seeking to undermine injustice) on the other. This connection between a reformist and a revolutionary thrust has constituted an opportunity for reaction and an impulse to bring about transformation: to transform by institutionalising, maintaining processes open and without standardisation.

The second strategic decision was to make the contradictions visible (and tolerable). The movement chose not to close its eyes to the suffering of mental illness, or what Basaglia called "the abnormal experience". Mental illness reveals several contradictions, as does its treatment. In this sense, mental illness is unbearable. On the other hand, not only mental illness but de-institutionalisation itself is an essentially contradictory process (which as we have seen is made up, at one and the same time, of 'institutionalising' processes and processes of negation of the 'institutionalised' and of its inertia).Aware of this situation, the movement chose to make irremediable contradictions visible, with a view to making them individually and collectively tolerable without concealing them (de Leonardis, 2006). In the words of Basaglia, the movement has sought to 'keep the contradictions open'. It has embarked on collective routes, looking to support a contradiction which remains in the open and which remains controlled. It has sought practical ways to uncover these contradictions and to make them tolerable without removing them or denying them. For this reason, the movement has strategically transformed the contradictions linked to mental illness and its treatment within a narrow policy sector from a private problem to a public issue, made visible for collective debate. Over the years, the experience of identifying contradictions and of setting up innovative practices of service have always taken shape through exchange and negotiation, conflict and compromise with other actors in the psychiatric sector, as well as with citizens and civil societies. The movement has always built conflict consciously, insofar as conflict is inherent in practices looking to confront the ways in 
which the weaker subjects are isolated from urban life. More precisely, the movement has always claimed conflict as a way to engage a larger section of the public in the issues of mental health, and to thus open the doors of the services for people to make their way in, whilst controlling the entry to and exit from these spaces (****, 2003).

\section{Social Entrepreneurship}

One working method in which these two strategies have taken shape is that of so-called 'social entrepreneurship'. This arises from the attempt to leave open the contradiction between assistance and enterprise for individuals with mental health problems, and to make this contradiction a producer of social innovation. In the language of the movement, the expression 'social entrepreneurship' is used to refer to 'enterprises that generate the social'. The appeal of enterprise lies in the action of its undertaking, and the experiences of social entrepreneurship take shape as forms of assistance which engage in an enterprise, investing in its main capital,which is the people. This is different from the experiences of the third sector seeking to 'undertake an enterprise in the social sphere', that is, to make an individual's disadvantaged condition profitable. Strategies of social entrepreneurship have often based themselves on simultaneous processes of professional training and work, catalysing and combining the energies of local contexts, and carrying out a restoration of both local resources and people's capacities. The practices of social entrepreneurship across the entire stretch of Italy are experiences of social innovation precisely because they invert the organisational logics of psychiatric services which tend to show vital flaws, chronic conditions and lack of ability, creating opportunities for profit and professionalisation together with the change of urban contexts. Such practices work by converting the budget destined for centres of containment and reclusion (such as the $\mathrm{PH}$ ) into investments for enterprises which produce services (mainly cultural services, but also environmental services, cateringrelated services, design, etc.). With respect to non-profit enterprises, which give greater priority to the provision of assistance to the disadvantaged members of the population (usually via social cooperatives defined by Law 381/1991 as being of type 'A', that is, precisely care and social services), their social entrepreneurship strategies constitute productive units which are equally non-profit, but which envisage the participation of disadvantaged partners (via social cooperatives of type ' $\mathrm{B}$ ', that is, those in which participate a certain quota of socially fragile subjects). In the case of the usual nonprofit enterprises, the receiver of assistance is the object of needs to be satisfied, 
whereas in the case of social entrepreneurship strategies, the receiver is the subject of capacities to be recognised and enhanced (de Leonardis, 1998:150).

The basic choice was a methodology of action to be adopted, with the final objective not of distributing benefits in order to fill a gap but of developing the capabilities of the former in-patients (see also Bonvin, Orton, 2009). Everyday practice involved a radical change in the style of care, no longer defining the beneficiaries in terms of their weaknesses, needs and lacks (to be defined and treated) but in terms of their capabilities (to be recognised and to be developed by using them). This methodology was defined thoroughly and coherently with the quality of the good it has to produce in mind: mental health is not something that could be produced, but only coproduced: co-production involves direct participation by those who will benefit from its production, and the quality of a good can be enhanced only if recipients are directly engaged in the production of that good (Ostrom E., 1996).

\section{A Case of Social Innovation: Olinda}

Despite the so-called 'Basaglia Law' in 1978 that decided the closure of all the PHs, at the beginning of the 90s the Milan PH 'Paolo Pini' was still open. Milan PH Paolo Pini has been built in 1921, with 27 buildings within a large park of $245.000 \mathrm{~m}^{2}$. By 1992 and with more than one hundred in-patients, there had been no serious effort to close the $\mathrm{PH}$ and to set up territorial networks of mental health services.

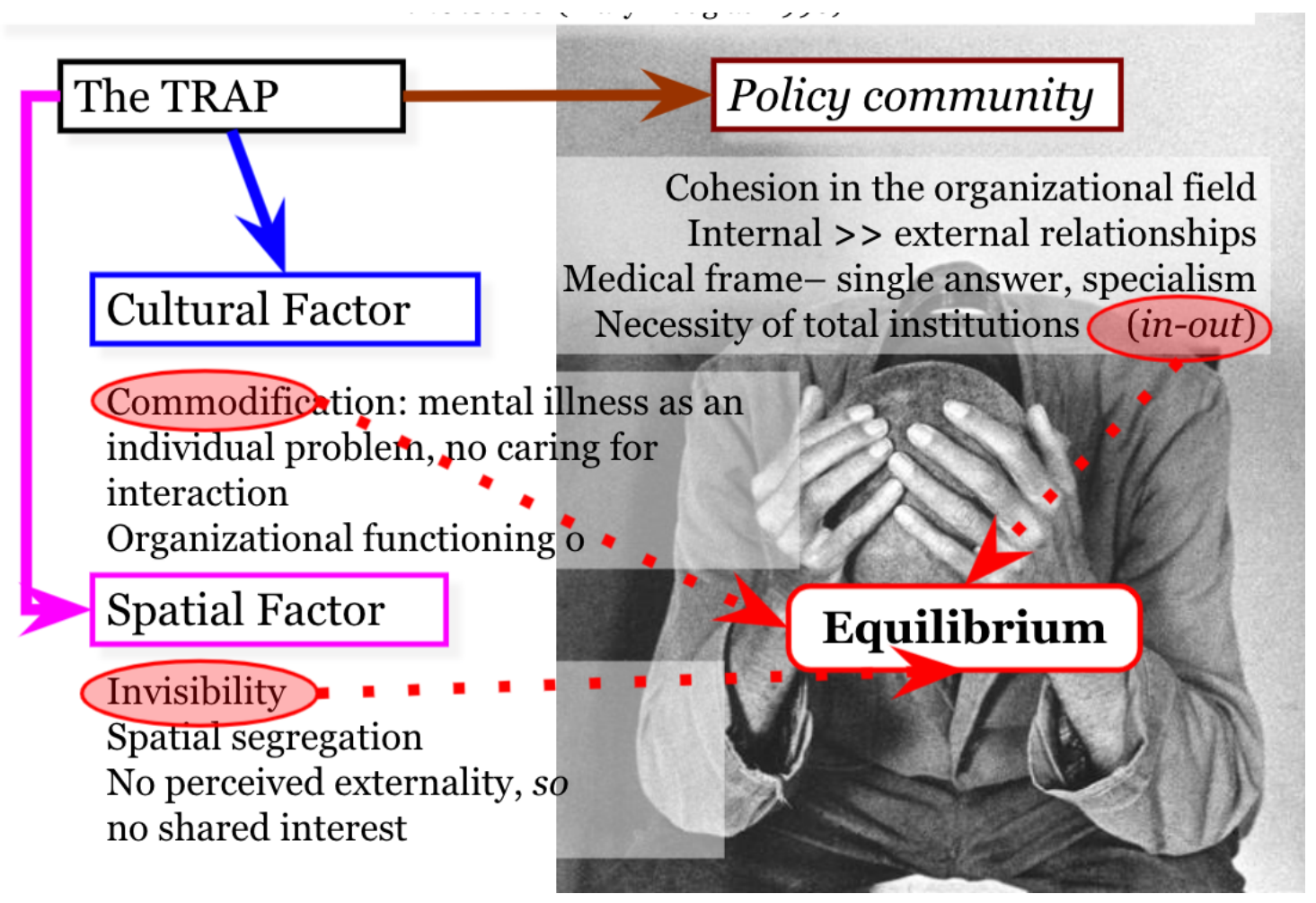


That same year, a Swiss psychiatrist came from Rome to work at the Milan PH. He belonged to the De-Institutionalization movement and brought with him a patrimony of ideas, strategies, and relationships acquired in the networks of the movement and in previous practical experiences of converting $\mathrm{PH}$ and starting up social entrepreneurships. He knew that a PH cannot be closed and its logic of functioning surpassed via decree law or injunctions alone. We identify three main stages in the social innovation process he enacted: the first is the period devoted only to vocational training with the in-patients of the $\mathrm{PH}$; the second is marked by the organization, in 1996, of a Summer Festival within the PH, with a large coalition of very different actors (PH in-patients, intellectuals, showmen/women, entrepreneurs, social workers, grassroots movements, and ordinary people); the last stage is the longest one beginning at the end of the festival and still on going, and is linked with the consolidation of the social entrepreneurship strategy.



\section{Broadening the Advocacy Coalition}

In the first stage, the Swiss Psychiatrist began working in the PH together with doctors and social workers, founding a team of professional trainers. He was an outsider in the narrow Milan mental illness policy sector, but he was not an outsider the policy sector 
itself. He persuaded the public Local Health Unit (USSL 37) to present an experimental project to the Lombardy Region Education and Vocational Training Sector and then he attracted and involved a large vocational training organization (ENAIP) ${ }^{3}$ and mobilized resources from EU programmes (especially ESF). The vocational training, although developing the skills of the in-patients and facilitating their integration into the labour market, was not an objective in itself. It was the first step in a broad strategy of social entrepreneurship. One of the main ideas of this strategy is that, in order to contrast the separation of $\mathrm{PH}$ from urban life, it is important to work on the thresholds of $\mathrm{PH}$, making them permeable, increasing the number and qualities of persons who can enter and of in-patients who can leave the institutuin. So in 1995, the first vocational training team founded the Olinda Association in order to mobilize more human resources into its projects. They involved many of the professionals (designers, artisans, technicians) distributed throughout the metropolitan area. The neighbourhood was not noticeably involved. The neighbouring area comprises lower urban middle-class and working-class inhabitants. During this first stage, relations were intense with the neighbourhood Health authorities, in particular with the hospitals of Niguarda and the corresponding Azienda Sanitaria (Public Local Health Board). Olinda also had relevant connections with the Milan Municipality (notably the Council for Culture) together with the Province and the Region. Long-term co-operation was also established with the Faculty of Political Science at the University of Milan, which produced some colloquia and an international conference at the Milan Chamber of Commerce about social entrepreneurship ("Cooperation, partnership and social entrepreneurship"). All these activities enabled the definition of the situation of the $\mathrm{PH}$ as problematic, opening up the opportunity to translate into Milan innovations already realized in other cities by the De-Institutionalisation movement.

\footnotetext{
${ }^{3}$ EnAIP is the biggest vocational training organization in the Lombardy Region: it is the 'ACLI National Board for Vocational Training', ACLI are 'International Christian Workers Associations'; but trainers involved in Milan PH are not linked with catholic hierarchies or involved into catholic movements.
} 


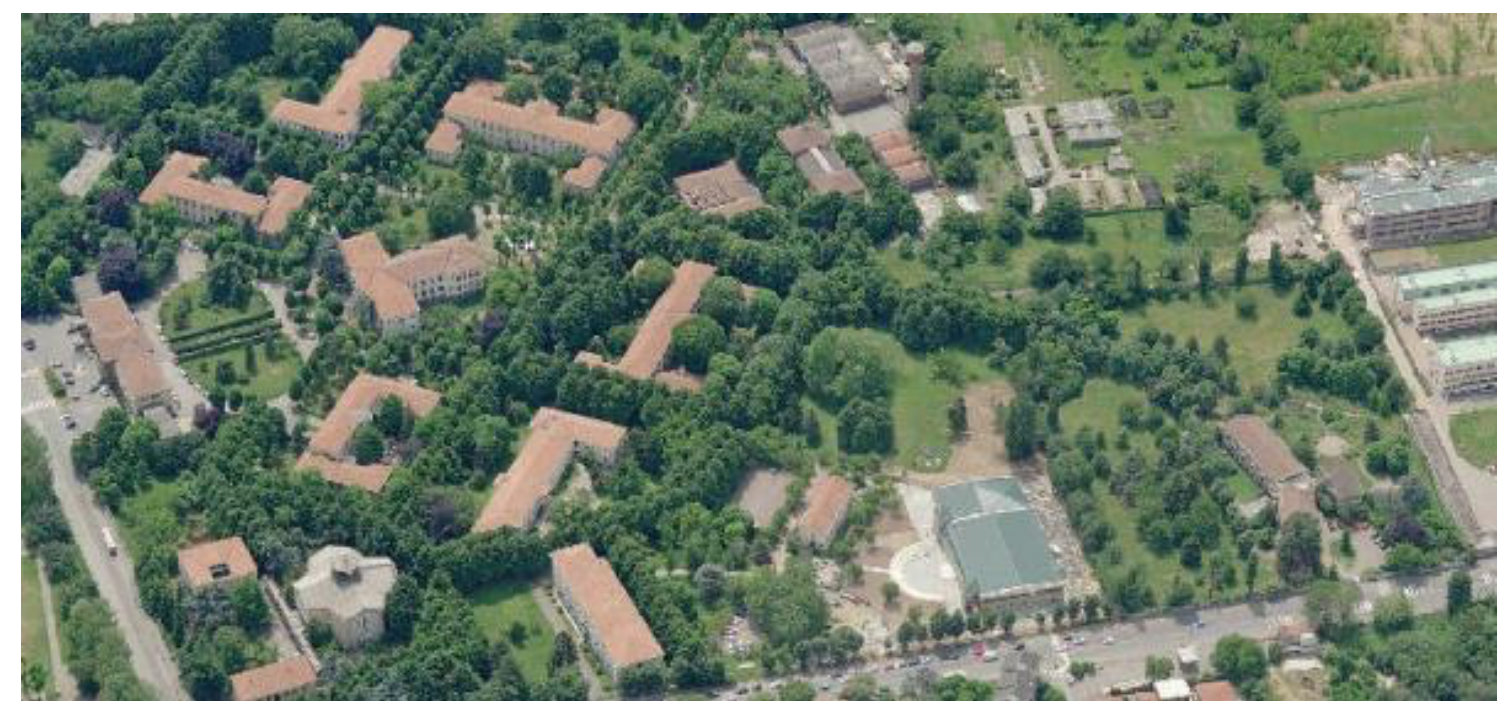

It seems to me that these activities produced a process of "enrolment" (Callon, 1986). In our context, enrolment means that the actors define each other's roles. Olinda promoted the redefinition of the role of outside actors and this led to the formation of an alliance of some of the institution's doctors and social workers, with some market entrepreneurs, a few university professors and people from show-business. It was not a big policy network, but it had boundaries completely different from the traditional Milan advocacy coalition network for mental illness policies and services.

\section{A Midsummer Night's Dream}

Thanks to previous experiences of the De-Institutionalisation movement, Olinda knew very well that processes of de-institutionalisation produce (and require) conflicts, so it acted intentionally to provoke conflicts and create public discussion on the $\mathrm{PH}$.

In December 1995, during the international conference in Milan about social entrepreneurship, in front of an audience of social workers, designers, managers, public officials, and intellectuals, a well-known priest - don Gino Rigoldi - launched the idea of a big festival in Milan. He did not propose a "Denunciation Festival", or a "Party in Solidarity with the Excluded", but a festival to enact partnerships, "where the process to accomplish is as important as the outcome" (quoting from the Olinda's catalogue).

Because of the apartness of the $\mathrm{PH}$ and of the narrowness of the former policy network, there was not a shared interest that could involve citizens to discuss and criticise the PH. Quite so, there were no social actions and transactions that generated externalities (like troubles and noise for the neighbourhood) and indirect consequences affecting the population outside the $\mathrm{PH}$. Without any perceived externality with the potential to create an interest in a mobilization for acquiring control over the action, no interest 
issue that may come to be regarded as a legitimate right emerges (Coleman, 1987). It is a situation without social capital, a system of "everybody for himself", without incentives for a collective action (ibidem: 153). Precisely, collective incentives were regulated to foster inertia and conservative equilibrium towards suboptimal social choices (Vitale, 2010). The processes of involving interests came about through practices of participation in which different actors learn to trust and work with one another and enable themselves to act collectively for common ends (Fung, 2004: 15). Soon, Olinda proposed to produce it inside the $\mathrm{PH}$, and worked to involve both some very important associations in Milan with different political leanings and some municipal and provincial councillors. The festival, named "A Midsummer Night's Dream", was jointly promoted by 33 different groups, associations and professional studios. It was rich in debates, music, sports activities, theatre shows, and recreational activities. Furthermore, a little piece of the PH wall was symbolically torn down during the festival. The festival attracted more than 35.000 people over a period of two months from the whole metropolitan area. However, the festival didn't appear to have particular success in the neighbourhood. Being accustomed to see the PH as a no-go area, the citizens of the adjoining neighbourhoods regarded Olinda's initiatives with suspicion, opposing and boycotting them, even by means of official complaints and political pressure. In addition, organised crime, in particular the Camorra - strongly represented in the outlying areas of Milan - tried several times to extort protection money, threatening the operators.

Indeed, 35.000 people 'enjoing' the PH was an extraordinary result. During the festival the $\mathrm{PH}$ was represented not as the symbolic core of social exclusion but as a place of resources, a potential cultural pole in the suburbs, a workshop full of projects designed with (and not for) the guests of the PH, projects meant for the whole town. The festival made a great contribution to legitimising Olinda's therapeutic innovations and made it possible to resume public debate over the continuing existence of the $\mathrm{PH}$, 18 years after the law decreeing its closure. It created lively exchanges concerning the elaboration of possible alternatives first of all for the in-patients but also for the spaces and the places within the PH. The festival was an effective way to convey information about the PH to officials, supporting the urgency of dismantling it, and shaming its perverse effects. Olinda enacted an open involvement context, a process in which the public as a whole and not only people implicated in the former policy network of mental health services, was the potential target of mobilization effort. So this process opened 
up the possibility of public debate on the quality of the psychiatric services in Milan and limited the opportunities for the scarce, opportunistic, routine action of the Health authorities and their governing boards. It seems to me that the festival introduced a strong discontinuity into the mental health policy sector. With thousands of people within the PH, things could not be taken for granted. This opened a stage of "epistemic choice" (Ostrom V., 1993; Ostrom E., Ostrom V., 2004: 133), wherein actors discussed criteria, vocabularies of analyzing and judging, and discovered new possibilities. This happened thanks to the attention of local mass media, to the diffusion of a little book publicising the Festival, but also to more informal means, especially to the presence within the PH of people, who could walk, ask and talk with the in-patients and the workers. A truly public arena (Cefaï, 2002) emerged. The presence of thousands of people during the festival within the boundary of the $\mathrm{PH}$ obliged the entire policy network to recount their policy aims and programmes for closing the $\mathrm{PH}$. Moreover, at the demand of the Health authorities, every policy actor was submitted to an imperative declaration of why and how to cope with people still living in the PH.

Before this mobilization the $\mathrm{PH}$ had been ignored, just perceived as a nuisance in the city life. But the legitimisation of the claim to close the PH permitted a large public to judge the trouble as a complex problem and to link together issues of mental health and of quality of life with the public responsibilities of the administrations. So Olinda played a mediation role (Vitale, 2019), producing a new advocacy coalition with very heterogeneous actors, to highlight the impasse and the closeness of the former policy network, and working at the cultural level to promote a different belief system about the PH and more generally about mental health policy. Similarly, in his research on the French city of Rennes, Patrick Le Galès (2001: 181) found that "at the local level, policy networks do not matter that much, but networks of actors, which are not specifically oriented towards one policy sector, matter very much".

\section{Constructing a Social Entrepreneurship}

The Summer Festival was not able to change the solid base of existing power relations or to gain strong control over policy processes, but permitted the emergence of a public discourse, the recognition of a sense of possibility in dealing with mental health problems, and legitimating new practices and claims. The fact that the space of the $\mathrm{PH}$ was accessible to the public was very important because this permitted it to be recognized as a stake, as a disputable public good, an object in need of regulation and governance. But the Festival did not obtain the immediate closing of the $\mathrm{PH}$. At the 
National level in the mid-nineties there was also an ongoing process aimed at the rapid phasing out of the system of PHs. In 1994, Law 724/94 set a 31 December 1996 deadline for the closure of the PHs. In 1996, Law 662/96 "confirmed their compulsory closure and defined the economic sanctions to be paid by those Regions that failed to comply with the so-called 'Plans to replace the PH' by 31 January 1997' (Macchi, 2003: 36). But the Milan PH was closed in 2000, 4 years after the Summer Festival; 22 years after the so-called 'Basaglia Law'.

The first festival generated many creative ideas for finding jobs for in-patients, as well as social capital to keep on enacting entrepreneurial projects and continuity of cultural activities. After the festival, Olinda continued working to develop ways to integrate various interests and networks within collective strategies and a loose but long-term mobilization. Olinda kept organising an annual summer festival following the route designed by the first one. In order to achieve its goals, Olinda continues to use the premises for its projects of social entrepreneurship, persisting in its plan to create work opportunities for former PH inmates, and also for other disadvantaged people involved through the local territorial psychiatric services, and for the inhabitants of the whole metropolitan area. In the year 2000, when the PH was closed, all the former inpatients found a place to live in small flats with public and private social workers, founded by public expenditure.

In 1998, Olinda Association also formed a social cooperative with disadvantaged workers referred from mental health services, establishing a carpentry workshop, a restaurant, a youth hostel, a café and a multimedia service. Olinda's basic idea is to organise and reorganise the mental health services so that they work towards producing social ties and social networks (Small, 2009; Vacca, et al., 2021) initiating assistance with enterprise following along the path traced by the De-Institutionalization movement. To do this, attention is concentrated both on the quality of exchange and synergy with public institutions (health services and local authorities - the Municipality, the Province, the Region), and on the quality of relationships with market exchange. That was particularly difficult, because in $\mathrm{PH}$, interagency collaboration is chronically difficult and "needs are rarely neatly compartmentalized to suit the requirements of administrative boundaries" (Jones et al., 2004: 110). In 2010, Olinda had a total of 29 workers, 50 continuative and 170 occasional volunteers.

Economic activities and market tests provide support to the autonomy of mentally ill people. Olinda has managed to take one step at a time, always using the 
human and economic resources available and drawing up sustainable feasibility plans. The first projects were small-scale and limited, although these were not considered temporary projects. They were linked to ambitious, sometimes 'foolish' expectations: the bar was to be open every day, the restaurant was to be full every lunchtime, cultural events were to draw a large public "in the very place that had to be closed by law, where the bars close at 7 p.m., where no-one sells books, where the craftsmen have disappeared, where culture has never been successful" (quoting from the Olinda's catalogue). It was to be a place where everybody could be at ease in their spare time, combining services for the city with services for mental health. Olinda is still trying to build a 'Public Square'.

\section{Social Entrepreneurship, Contradiction and Social Innovation}

Over the years Olinda has succeeded in activating, extending, and coordinating a range of people, and in achieving the recognition and use of the premises of the $\mathrm{PH}$ as a public area. Where did it find the resources for doing all this things? I argue that the network of the De-Institutionalisation movement has sustained Olinda, offering important cognitive resources and opportunities, and the example of its own way of organising. As we have seen in the second paragraph, the organizational dimension, in particular the style of organizing, is very important. Social innovation needs "reflexivity" and resilience for learning and adapting. This does not mean that these are the only conditions for social innovation (Tosi, 2004) but the Olinda case allows us to focus on the importance of contradictions in sustaining reflexivity in organising processes.

At the very core of Olinda, as in every experience of social entrepreneurship, we can find a main contradiction: the one between the logic of care and the logic of work. This contradiction is at the same time a strategic purpose declared and invoked by the De-Institutionalisation movement and an organisational form. Looking at the Olinda case, it seems to me that this contradiction has avoided the risk of 'heterogenesis of the ends', a well known organizational dynamic. Organizations tend to reproduce themselves, inverting means and ends. But the presence of two very contradictory goals within the same organization (what I have called the logic of care and the logic of work) creates continuous tensions and conflicts that offer room for reflexivity, organizational learning and resilience (Thévenot, 2001).

The contradiction between care and work has led Olinda to be almost constantly involved in organisational dilemmas. In analytical terms, I could say that in order to halt 
social exclusion, Olinda has attempted to create connections between opposites (de Leonardis, 2006), maintaining the contradictions open and endeavouring to establish continous connections between the experience of the inpatients and the experience of users of the Park of the $\mathrm{PH}$; between the need for provisions for welfare and a strategy of investments in the economic field of production; between the neighbourhood and the metropolitan area; ${ }^{4}$ (d) between an institutional face (as a condition for commitments in partnerships) and a contentious one. Olinda tries to increase the circulation between different levels of engagement, incrementing the most as possible the internal plurality, looking for organizational forms of coherence between different level of commonality in the plural (Thévenot, 2007).

\section{By product}

Closing the $\mathrm{PH}$

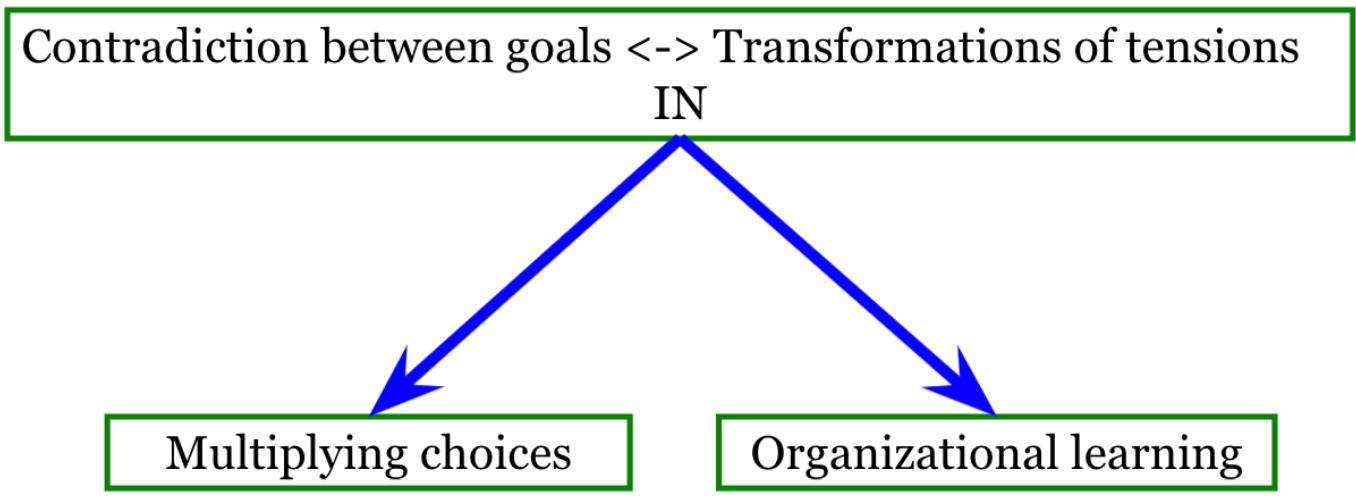

One of the most important organizational means Olinda has found to manage its constitutive contradiction is the presence of an "association" alongside the co-operative. In fact Olinda is both both a voluntary association and a social cooperative. In this dualism lays the basis for cultural and creative elaboration and thus represents: (a) for the organisation internally, a way of circulating ideas, sharing problems and successes

4 In the preliminary two stages Olinda has opposed the idea of involving the neighbourhood.

Rather than "developing a community", it has sought "injections of society in the neighbourhood". After the closing of the $\mathrm{PH}$, Olinda has practised a more determined strategy of collaboration with local associations and supporting groups of parents who organise recreational activities for the neighbourhood children. 
and re-elaborating a shared identity and mission; (b) for the environment, a means of raising visibility and communicating with the contexts where action is taken, and a tool for cultural exchange and attracting resources; (c) the dual definition as association and as co-operative makes it possible to keep the links between entrepreneurial objectives and social aims open and alive.

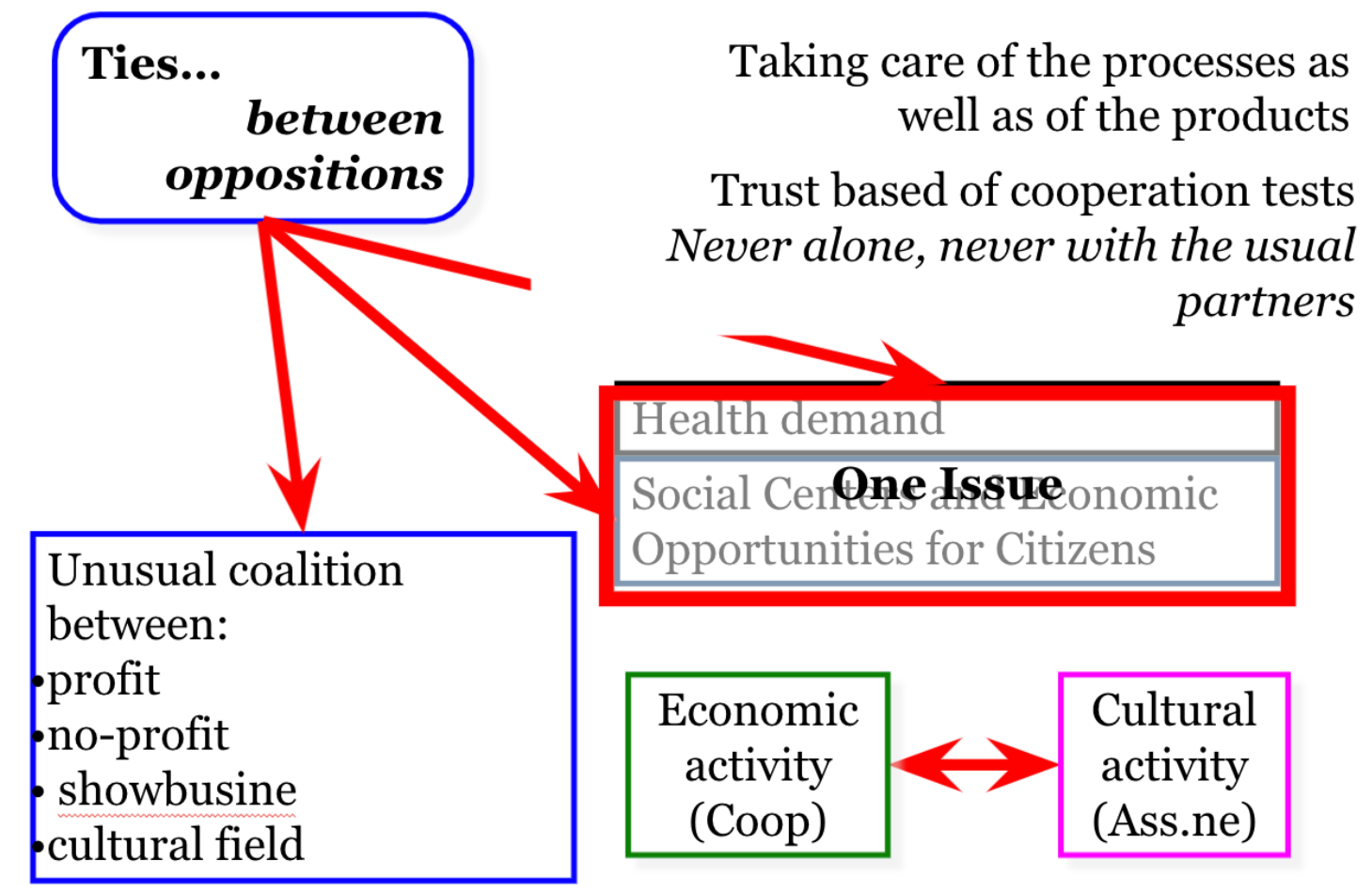

Olinda initially received considerable contributions from local public bodies (the Region, the Province and the Milan Municipality, provided by their respective cultural sectors in the form of contracts renewable yearly). Today most of the economic resources are obtained from the sale of products/services linked to the cultural or production activities (in particular the bar/restaurant and the carpenters' workshop, while the hostel and the multimedia sector are still in the incubation phase) and from occasional contributions from local banks Foundations. Since 2000 over three quarters of the turnover (90\% in the Cooperative) revolves around the production activities. These resources are integrated by indirect contributions in the form of facilities from the Niguarda Hospital Board (e.g. the premises of the cultural and production activities, in the form of payment of utilities and maintenance fees). To this should be added the activities and services carried out within projects run jointly with other associations, with which Olinda has established partnerships (e.g. in 1998-1999 a Horizon 
employment project, in 2001-2004 two EQUAL projects or a professional training project with the Regional Authorities of Lombardy).

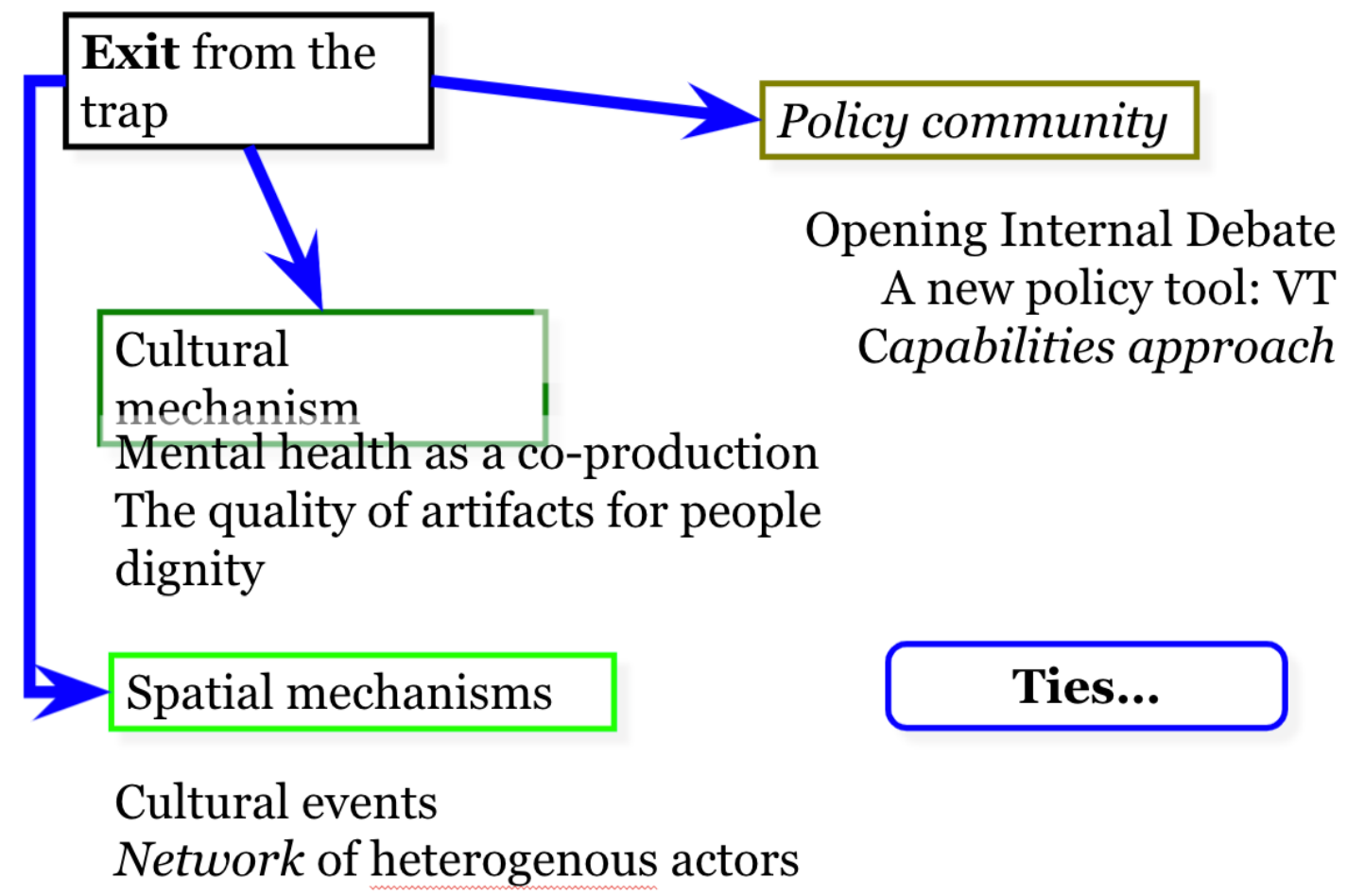

Looking at its strategies doe not mean that Olinda is a full 'strategic actor', i.e. a collective actor able to manage information and calculate the consequences of its 'games'. Olinda is limited in its capacity to be a strategic actor. It has difficulties in moving from a short-term to a medium or long-term horizon; it lacks the necessary conditions for doing so, in particular security regarding its location in the future. Olinda's activities, both of a social and a productive nature, take place inside the buildings of the former PH, the ownership of which is unclear. Since the closure of the PH the authorities have not precisely established the sub-division of ownership of the buildings and the land, which are the subject of contention by the Province, the Region and the Hospital Board. In practice, Olinda thus has its offices and workshops, as well as a restaurant and a hostel, on public property of which the ownership is unclear, and its right to use these is therefore not guaranteed by any form of written contract. Nonetheless, the use of the area and its buildings is not regarded as illegal occupation, since it is supported and recognised by the local institutions. This uncertainty makes it very difficult to invest in the spaces and buildings it uses and to acquire a more strategic long-term outlook. But, without having premises to make a long-term planning, Olinda is still keeping up its activities within its institutional mandate and in pursuit of its goals, trying to translate dilemmas into opportunities (and compromises). The 
contradiction between the logic of work and the logic of care shapes an organising style of reflective 'fallible learners' (Ostrom, Ostrom, 2004). As in many other social innovations, people from Olinda "learn as they act and from experience, and hence have the potential to act as creative transformers' (Gonzalez, Healey, 2005).

Therefore, what is clear in the Olinda case is the considerable circulation of cognitive resources and knowledge within the organisation, and particularly the strong emphasis on reflexivity in organising, involving and combining human resources coming from different scales and from spheres traditionally far removed from that of social work (fashion, design, art, entertainment) to respond to its contradictory aims (Vitale, 2009). In this sense the contradictions of ends at the core of the social entrepreneurship strategy sustain a high degree of reflexivity. Learning and resilience are due primarily not only to the presence of a leader but also to the style of organizing, and to the connections with a broader social movement. As Moulaert et al. (2005) stressed, movements for change are at the core of the dynamics of social innovation, especially for their vision of organizational culture. As we have seen, the fact that Olinda refers to a tradition of social innovation coming from a social movement, obviously does not mean that it simply reproduces this tradition into the Milan context, but that Olinda mobilise ideas, repertoires of actions, evaluative criteria, and even working routines for collective action (Borghi, Vitale, 2007) already tested in this social movement. These are fundamental resources to escape from the trap of localism and inertial closed policy community in the health sector.

\section{References}

Basaglia F, 1987 Psychiatry Inside Out (Columbia University Press, New York) Boltanski L, Thévenot L, 2006 On Justification (Princeton University Press, Princeton) Bonvin J.-M., Orton M., 2009, "Activation policies and organisational innovation" International Journal of Sociology and Social Policy 29 (11/12) 564 - 574

Borghi V, Vitale T., 2007, Le convenzioni del lavoro, il lavoro delle convenzioni (FrancoAngeli, Milano)

Callon M, 1986, "Some Elements of a Sociology of Translation", in Power, Action and Belief. Ed. J Law (Routledge, London) pp. 196 - 223

Calvino I, 1978 Invisible Cities (Harvest Books, New York)

Cefaï D, 2002, “Qu'est-ce qu'une arène publique?", in L'héritage du pragmatisme. Eds D Cefaï, I Joseph (Editions de l'Aube, La Tour d'Aigues) pp 51 - 81

Coleman J S, 1987, "Norms as Social Capital", in Economic Imperialism. Eds G. Radnitzky, P. Bernholz (Paragon House Publishers, New York) pp 133 - 53

De Leonardis O, 1986, "Il caso del movimento psichiatrico italiano", in Movimenti sociali e sistema politico Ed. A Melucci (FrancoAngeli, Milan) pp 197 - 204 
De Leonardis O, 1990 Il terzo escluso. Le istituzioni come vincoli e come risorse (Feltrinelli, Milan)

De Leonardis O, 1998 In un diverso welfare. Sogni e incubi (Feltrinelli, Milan)

De Leonardis O, 2006, "Social Capital and Health" European Journal Of Social Quality 6 (2) $19-51$

De Leonardis O, Mauri D, Rotelli F, 1996, "Deinstitutionalisation, Another Way" Health Promotion 1151 - 165

Diani M, 2000, "Simmel to Rokkan and Beyond" European Journal of Social Theory 3 $387-406$

Donolo C, Fichera C (eds), 1988 Le vie dell'innovazione (Feltrinelli, Milan)

Eliasoph N, Lichterman P, 2003, "Culture in Interaction" American Journal of Sociology 108735 - 94

Elster J, 1979, "Négation active et négation passive" Archives Européennes de Sociologie 21329 - 349

Fung A, 2004 Empowered Participation (Princeton University Press, Princeton)

Giannichedda M G, 2005, "Introduzione", in L'utopia della realtà, Ed. F O Basaglia (Einaudi, Torino) pp VII-LII

Goffman E, 1961 Asylums (Anchor Books, New York)

Gonzalez S, Healey P, 2005, "A Sociological Institutionalist Approach to the Study of Innovation in Governance Capacity" Urban Studies 11, 2055 - 2069

Hillier J, Moulaert F, Nussbaumer J, 2004, "Trois essais sur le rôle de l'innovation sociale dans le développement spatial” Géographie, Economie, Société 6, 19 42

Jones N, Thomas P, Rudd L, 2004, "Collaborating for Mental Health Services in Wales: A Process Evaluation" Public Administration 82109 - 21

Le Galès P, 2001, "Urban Governance and Policy Networks" Public Administration 79 $167-184$

Macchi S, 2003, "The 'Citadel of Exclusion"”, in Knights and Castles: Minorities and Urban Regeneration Eds F Lo Piccolo, T Huw (Ashgate, Aldershot) pp 33 - 48

Mauri D (ed.), 1983 La libertà è terapeutica? L'esperienza psichiatrica di Trieste (Feltrinelli, Milan)

Membretti A, 2007, "Centro Sociale Leoncavallo. Building Citizenship as an Innovative Service" European Journal of Urban and Regional Studies 14 (3) 252 - 263

Moulaert F, Martinelli F, Swyngedouw E, Gonzalez S, 2005), "Towards Alternative Model(s) of Local Innovation" Urban Studies 111969 - 1990

Moulaert F, Nussbaumer J, 2005, “The Social Region” European Urban and Regional Studies $1245-64$

Moulaert F, Sekia F, 2003, "Territorial Innovation Models: a Critical Survey" Regional Studies 37289 - 302

Moulaert F, Swyngedouw E, Martinelli F, González S (eds), 2010 Can Neighbourhoods Save the City? (Routledge, London)

Ostrom E, 1996, "Crossing the Great Divide: Coproduction, Synergy, and Development" World Development 2473 - 87

Ostrom E, Ostrom V, 2004, "The Quest for Meaning in Public Choice" The American Journal of Economics and Sociology $63105-147$

Ostrom V, 1993, "Epistemic Choice and Public Choice" Public Choice 77163 - 176

Pratschke J, Vitale T, Morelli N, Cousin B, Piolatto B \& Del Fabbro M, 2021, "Electoral support for the 5 Star Movement in Milan: An ecological analysis of social and spatial factors", Journal of Urban Affairs

DOI: $10.1080 / 07352166.2021 .1886855$ 
Small M, 2009, Unanticipated Gains. Origins of Network Inequality in Everyday Life (Oxford University Press, Oxford)

Swyngedouw E., 2005, “Governance Innovation and the Citizen" Urban Studies 11 $1991-2006$

Tarrow S, 1990 Democracy and Disorder: Protest And Politics In Italy 1965-75 (Oxford University Press, Oxford)

Thévenot L, 2001, “Organized Complexity” European Journal of Social Theory 4405 425

Thévenot L, 2007, "The plurality of cognitive formats and engagements" European Journal of Social Theory 3413 - 427

Tosi S, 2004 Azioni locali nella crisi del welfare state (Libreria Clup, Milan)

Vacca R, Cañarte D \& Vitale T, 2021, "Beyond ethnic solidarity: the diversity and specialisation of social ties in a stigmatised migrant minority" Journal of Ethnic and Migration Studies, DOI: 10.1080/1369183X.2021.1903305

Vitale T, 2009, "Politique des évictions. Une approche pragmatique", in Cantelli F., Roca i Escoda M., Stavo-Debauge J., Pattaroni L. (eds), Sensibilités pragmatiques. Enquêter sur l'action publique, Bruxelles, P.I.E. Peter Lang, pp. $71-92$

Vitale T, 2010, "Regulation by Incentives, Regulation of the Incentives in Urban Policies" Transnational Corporations Review 2 2, pp. 58-68. DOI: 10.5148/tncr.2010.1044

Vitale T, 2015, "Territorial Conflicts and New Forms of Left-Wing Political Organization: from Political Opportunity Structure to Structural Contexts of Opportunities" Sociologica. Italian journal of sociology on line 9 3. DOI: $10.2383 / 82475$.

Vitale T, 2019, "Conflicts on Roma Settlements in Italian Cities: Normative Polarisation and Pragmatic Mediation" Palaver 8 1, pp. 29-74. DOI: 10.1285/i22804250v8i1p29.

Weick K, 1995 Sensemaking in Organizations (Sage, London) 